\title{
Allyl isothiocyanate triggers G2/M phase arrest and apoptosis in human brain malignant glioma GBM 8401 cells through a mitochondria-dependent pathway
}

\author{
NIAN-GU CHEN ${ }^{1}$, KUAN-TIN CHEN $^{3}$, CHI-CHENG LU ${ }^{2}$, YU-HSUAN LAN ${ }^{4}$, \\ CHENG-HUNG LAI ${ }^{1}$, YANG-TSUNG CHUNG ${ }^{1}$, JAI-SING YANG ${ }^{5}$ and YUNG-CHANG LIN ${ }^{1}$ \\ Departments of ${ }^{1}$ Veterinary Medicine, ${ }^{2}$ Life Sciences, National Chung Hsing University, \\ Taichung 402; ${ }^{3}$ School of Medicine, ${ }^{4}$ School of Pharmacy, ${ }^{5}$ Department of Pharmacology, \\ School of Medicine, China Medical University, Taichung 404, Taiwan
}

Received February 12, 2010; Accepted April 16, 2010

DOI: $10.3892 /$ or_00000878

\begin{abstract}
Isothiocyanates (ITCs) are present as glucosinolates in various cruciferous vegetables. Allyl isothiocyanate (AITC) is one of the common naturally occurring isothiocyanates. Recent studies have shown that AITC significantly inhibited survival of leukemia HL-60, bladder cancer UM-UC-3 and colon cancer HT-29 cells in vitro. In this study, we demonstrate that AITC significantly decreased proliferation and viability of human brain malignant glioma GBM 8401 cells in a dose-dependent manner with $\mathrm{IC}_{50} 9.25 \pm 0.69 \mu \mathrm{M}$ for 24 h-treatment. The analysis of cell cycle distribution also showed that AITC induced significantly G2/M arrest and sub-G1 phase (apoptotic population) in GBM 8401 cells AITC markedly reduced the CDK1/cyclin B activity and protein levels by CDK1 activity assay and Western blot analysis. AITC-induced apoptotic cell death and this evidence was confirmed by morphological assessment and DAPI staining. Pretreatment with specific inhibitors of caspase-3 (Z-DEVE-FMK) and -9 (Z-LEHD-FMK) significantly reduced caspase- 3 and -9 activity in GBM 8401 cells. Western blot analysis and colorimetric assays also displayed that AITC caused a time-dependent increase in cytosolic cytochrome $c$, pro-caspase-9, Apaf-1, AIF, Endo G and the stimulated caspase- 9 and -3 activity. Our results suggest that AITC is a potent anti-human brain malignant glioma drug and it shows a remarkable action on cell cycle arrest before commitment for apoptosis is reached.
\end{abstract}

Correspondence to: Professor Yung-Chang Lin, Department of Veterinary Medicine, National Chung Hsing University, 250, Kuo Kuang Road, Taichung 40227, Taiwan

E-mail: ylin@nchu.edu.tw

Dr Jai-Sing Yang, Department of Pharmacology, China Medical University, No. 91, Hsueh-Shih Road, Taichung 40402, Taiwan E-mail: jaising@mail.cmu.edu.tw

Key words: allyl isothiocyanate, human brain malignant glioma GBM 8401 cells, apoptosis, mitochondria, G2/M arrest

\section{Introduction}

Glioblastoma multiforme (GBM) is a common and lethal primary malignant brain tumor (1). In the primary GBM, the 2-year survival rate is $<5 \%$ (2). During the last two decades, many treatments for GBM, including surgical therapy, radiotherapy and chemotherapy were suggested. However, the GBM survival rate has not changed (3). With the mechanisms of GBM revealed gradually (4), treatments have been focused on reducing tumor growth or inducing apoptosis mechanisms to improve survival. So far, the therapy for brain tumors in clinic is still unsatisfactory.

Discovery of anti-cancer agents from dietary natural products provides a useful application and chemotherapeutic effectiveness on cancer cells (5), and many studies have focused on killing cancer cells through the promotion of cell cycle arrest and induction of apoptosis $(6,7)$. The protein levels of CDK1 with cyclin B play vital roles in the regulation of $\mathrm{G} 2 / \mathrm{M}$ phase $(8,9)$. Otherwise, apoptotic cell death is important after tumor cell exposure to bioactive dietary natural compound, phytochemicals or anti-cancer drugs (10-12).

Apoptotic cell death is divided into two major signaling pathways. The death receptor pathway (extrinsic) begins outside the cell through the activation of the cell surface (Fas/FasL or TRAIL) and then promotes caspase- 8 activation $(13,14)$. In the mitochondrial pathway (intrinsic), death signals to mitochondria result in the release of mitochondrial intermembrane proteins such as cytochrome $c$, which associate with apoptotic protease-activating factor 1 (Apaf-1) and procaspase- 9 to form the apoptosome and then active caspase- 3 leading to cell apoptosis $(14,15)$. In addition, the caspaseindependent pathway is involved in the mitochondria which leads to release of AIF or Endo G from mitochondria causing cell death $(16,17)$.

Isothiocyanates (ITCs) are present as glucosinolates in various cruciferous vegetables. Allyl isothiocyanate (AITC) is one the common naturally occurring ITCs (18). Many studies have found that AITC can inhibit cancer cell proliferation by causing cell cycle arrest and/or induction of apoptosis, including human leukemia, bladder cancer, cervical cancer and colorectal cancer cell lines (19-22). 
However, no previous study exists addressing whether the AITC inhibits cell proliferation, promotes cell cycle arrest and induces apoptosis in human brain malignant glioma cells. The aim of the present study was to determine and explore AITC-triggered G2/M phase arrest and cell death in GBM 8401 cells via a mitochondria-dependent apoptotic signaling.

\section{Materials and methods}

Chemicals and reagents. Allyl isothiocyanate (AITC), propidium iodide (PI), Triton X-100, RNase A, Tris-HC1 and MTT [3-(4,5-dimethylthiazol-2-yl)-2,5-diphenyltetrazolium bromide] were purchased from Sigma Chemical Co. (St. Louis, MO, USA). RPMI-1640 medium, fetal bovine serum (FBS), L-glutamine, penicillin-streptomycin and trypsinEDTA were obtained from Gibco BRL/Invitrogen Corp. (Grand Island, NY, USA). Caspase-9 inhibitor (Z-LEHDFMK), caspase-8 inhibitor (Z-IETD-FMK) and caspase-3 inhibitor (Z-DEVD-FMK) (R\&D Systems, Minneapolis, MN, USA) were dissolved in DMSO and diluted in cell culture medium before use.

Cell culture. Human brain malignant glioma cell line (GBM 8401) was purchased from the Food Industry Research and Development Institute (Hsinchu, Taiwan). Cells were plated onto $75 \mathrm{~cm}^{2}$ tissue culture flasks in RPMI-1640 medium supplemented with $10 \% \mathrm{FBS}, 100 \mathrm{U} / \mathrm{ml}$ penicillin, $100 \mu \mathrm{g} / \mathrm{ml}$ streptomycin and $2 \mathrm{mM} \mathrm{L-glutamine}$ and grown at $37^{\circ} \mathrm{C}$ under a humidified $5 \% \mathrm{CO}_{2}$ and $95 \%$ air at one atmosphere. Subconfluent cells were passaged with a solution containing $0.25 \%$ trypsin and $0.02 \%$ EDTA (23).

Cell morphological examination. About $2 \times 10^{5}$ cells/well of GBM 8401 cells in a 12-well plate were treated with 0,10 , and $20 \mu \mathrm{M}$ of AITC and then were incubated for 24 and $48 \mathrm{~h}$. Cells were directly examined and were photographed under contrast-phase microscope (24).

Determination of cell viability by MTT assay. About $1 \times 10^{4}$ cells/well of GBM 8401 cells in 96-well plates were exposed to $0.5,1,5,10$, and $20 \mu \mathrm{M}$ of AITC, and DMSO, $0.1 \%$ in media served as a vehicle control. After a $24 \mathrm{~h}-$ incubation, $100 \mu \mathrm{l}$ of MTT $(0.5 \mathrm{mg} / \mathrm{ml})$ solution was added to each well, and the plate was incubated at $37^{\circ} \mathrm{C}$ for $3 \mathrm{~h}$. An aliquot $(100 \mu 1)$ of $0.04 \mathrm{~N} \mathrm{HCl}$ in isopropanol was added and the absorbance at $570 \mathrm{~nm}$ was measured for each well. The cell survival ratio was expressed as \% of control (25).

Cell cycle distribution analysis. The GBM 8401 cells were seeded onto 12 -well culture plates at $2 \times 10^{5}$ cells/well then incubated with $10 \mu \mathrm{M}$ of AITC for $24 \mathrm{~h}$. The cells were harvested and washed by centrifugation. For cell cycle and apoptosis determination, cells were fixed by $70 \%$ ethanol in $-20^{\circ} \mathrm{C}$ overnight and then re-suspended in PBS containing $40 \mu \mathrm{g} / \mathrm{ml}$ PI and $0.1 \mathrm{mg} / \mathrm{ml}$ RNase A and $0.1 \%$. Triton X-100 in dark room for $30 \mathrm{~min}$. The cell cycle distribution and apoptotic nuclei were determined by flow cytometry (FACSCalibur ${ }^{\mathrm{TM}}$, Becton Dickinson, Franklin Lakes, NJ, USA) (26).
Assessment of apoptosis morphology by DAPI staining. Approximately $2 \times 10^{5}$ cells/well of GBM 8401 cells in a 12well plate were treated with 0 , and $10 \mu \mathrm{M}$ of AITC and $0.1 \%$ DMSO as the control. Cells were incubated and grown for 24 h. Cells were stained by 4'-6-diamidino-2-phenylindole (DAPI, Molecular Probes/Invitrogen Corp., Eugene, OR, USA) and were examined and photographed under fluorescence microscopy (24).

CDK1 kinase assay. According to the protocol of Medical and Biological Laboratories CDK1 kinase assay kit (MBL, Nagoya, Japan). About $1 \times 10^{7}$ cells were suspended in a buffer containing, in a final volume of $0.2 \mathrm{ml}, 50 \mathrm{mM}$ Tris-HC1 (pH 7.5), $1 \mathrm{mM}$ phenylmethylsulfonyl fluoride, $50 \mathrm{pg} / \mathrm{ml}$ leupeptin, $10 \mathrm{mM}$ 2-mercaptoethanol, $1 \mathrm{mM} \mathrm{MgCl}_{2}, 2 \mathrm{mM}$ EGTA, 0.5 mM dithiothreitol, 0.01\% Brij35, $25 \mathrm{mM}$ $b$-glycerophosphate, and $0.5 \mathrm{M} \mathrm{NaCl}$. Cell suspensions were sonicated and centrifuged at $10,000 \mathrm{x}$ g for $30 \mathrm{~min}$. To determine the CDK1 kinase assay condition using MV Peptide and determined by measuring OD 492 as described previously $(27,28)$.

Western blot analysis. About $1 \times 10^{7}$ cells of GBM 8401 in a 75-T flask were treated with $10 \mu \mathrm{M}$ of AITC for $0,6,12,24$ and $48 \mathrm{~h}$. The examined cells were harvested and washed with cold PBS for detecting the changes of protein levels correlated with $\mathrm{G} 2 / \mathrm{M}$ phase-modulated and apoptotic signaling. The total proteins were collected from ATIC-treated GBM 8401 cells before the CDK1, cyclin B and cyclin A were detected and measured as previously described (28). The level of cytosolic fraction proteins such as cytochrome $c$, Apaf-1, pro-casepase9, AIF, and Endo G were determined and isolated according to the manufacturer's protocol (Mitochondria/Cytosol fractionation kit, BioVision, Inc. Mountain View, CA, USA). GBM 8401 cells after exposure to AITC were harvested, disrupted and then centrifuged to isolate cytosolic fractions as described elsewhere $(24,29)$. The total or cytosolic protein $(40 \mu \mathrm{g})$ from each sample was resolved on $12 \%$ sodium dodecylsulfate polyacrylamide gel electrophoresis (SDS-PAGE) and transferred to nitrocellulose membrane. The blot was soaked in blocking buffer (5\% non-fat dry mik/0.05\% Tween-20 in $20 \mathrm{mM}$ TBS at pH 7.6) at room temperature for $1 \mathrm{~h}$ and then incubated with anti-CDK1, anticyclin B, anti-cyclin A, anti-cytochrome $c$, anti-Apaf-1, antipro-casepase-9, anti-AIF, and anti-Endo G antibodies (Santa Cruz Biotechnology, Inc.) in blocking buffer at $4{ }^{\circ} \mathrm{C}$ overnight. A secondary antibody horseradish peroxidase conjugate was added and detected by chemiluminescence and autoradiography using X-ray film. To ensure equal protein loading, each membrane was stripped and reprobed with antiß-actin antibody.

Assays for caspase-3, -8 and -9 activities. Approximately $1 \times 10^{7}$ cells of GBM 8401 in a 75-T flask were pretreated with or without the selective inhibitors (Z-DEVE-FMK for caspase-3, Z-IETD-FMK for caspase- 8 and Z-LEHD-FMK for caspase-8) and then treated with $10 \mu \mathrm{M}$ AITC were incubated for $24 \mathrm{~h}$ to detect caspase-3, -8 and -9 activities. Caspase-3, -8 and -9 activities were assessed according to the manufacturer's instructions (Caspase colorimetric kit, R\&D 
$\mathbf{A}$

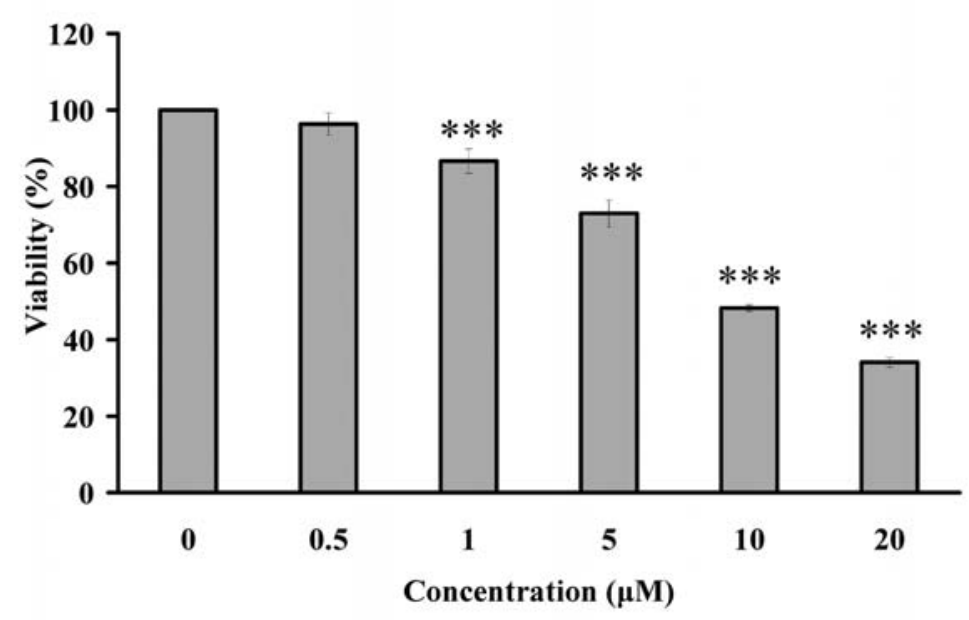

B

$24 \mathrm{~h}$

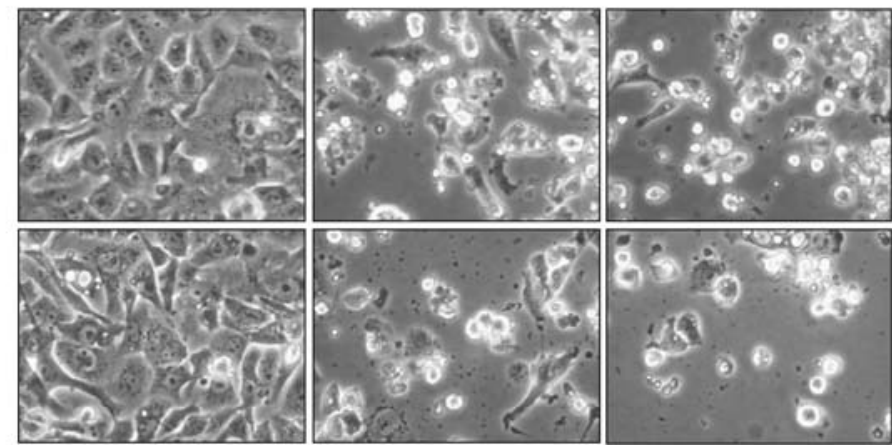

Control

$\operatorname{AITC}(10 \mu \mathrm{M})$

$\operatorname{AITC}(20 \mu \mathrm{M})$

Figure 1. Effects of AITC on cell viability (A) and morphology (B) of GBM 8401 cells. Cells were cultured with $0,0.5,1,5,10$ and $20 \mu \mathrm{M}$ of AITC for $24 \mathrm{~h}$. Viable cells were determined by MTT assay. The cell morphological changes were examined and photographed under phase-contrast microscopy (x200) as described in Materials and methods. There was a significant difference $\left.{ }^{* * * *} \mathrm{P}<0.001\right)$ when compared with the control group by Student's t-test analysis.

System Inc.). Briefly, cells were harvested and lysed in $50 \mu 1$ lysis buffer containing $2 \mathrm{mM}$ DTT for $10 \mathrm{~min}$. After centrifugation, the supernatants containing $100 \mu \mathrm{g}$ proteins were incubated with caspase-3, -8 and -9 substrate in reaction buffer. Samples were incubated in a 96-well flat bottom microplate at $37^{\circ} \mathrm{C}$ for $1 \mathrm{~h}$. Levels of released pNA (Z-DEVEpNA, Z-IETD-pNA and Z-LEHD-pNA for caspase-3, -8 and -9 , respectively) were measured with an ELISA reader (Anthos Labtec Instruments) at OD $405 \mathrm{~nm}$ wavelength $(27,30)$.

Statistical analysis. Student's t-test was used to analyze the differences between the AITC-treated and control groups. All data were expressed as mean \pm SD from at least three independent experiments. $\mathrm{P}<0.05, \mathrm{P}<0.01$ and $\mathrm{P}<0.001$ were indicative of significant difference.

\section{Results}

Cytotoxic effects and morphological changes of AITC on human brain malignant glioma GBM 8401 cells. The potential cytotoxicity of AITC on a human brain malignant glioma cell line GBM 8401 was investigated by the MTT assay. The results are presented in Fig. 1A showing that
AITC significantly reduced the percentage of viable cells as compared to control cells and these effects were dosedependent. The $\mathrm{IC}_{50}$ of AITC was $9.25 \pm 0.69 \mu \mathrm{M}$ after $24 \mathrm{~h}$ treatment. Also, the examined cells exhibited morphological changes, including rounding and shrinkage after 24 and 48 h-incubation with 10 and $20 \mu \mathrm{M}$ of AITC as shown in Fig. 1B.

Effects of AITC on cell cycle progression and apoptotic cell death. AITC induced reduction of cell viability could be due to apoptosis (sub-G1 population) mediated by cell cycle arrest which were determined. Representative profiles of cell cycle progression and percentage of each phase are presented in Fig. 2A. Significant arrest was seen at $\mathrm{G} 2 / \mathrm{M}$ phase at $10 \mu \mathrm{M}$ of AITC and it significantly increased apoptotic cells (sub-G1 groups) (Fig. 2A). It can be seen in Fig. 2B that apoptotic chromatistic (nuclear and chromatin condensation) in GBM 8401 cells occurred with or without AITC $(10 \mu \mathrm{M})$ treatment for $24 \mathrm{~h}$ determined by DAPI staining.

AITC modulated relative regulated protein levels of $G 2 / M$ phase. In order to confirm ATIC-induced an accumulation of G2/M population in GBM-8401 cells and it was regulated associated proteins. GBM 8401 cells after exposure to AITC 
A

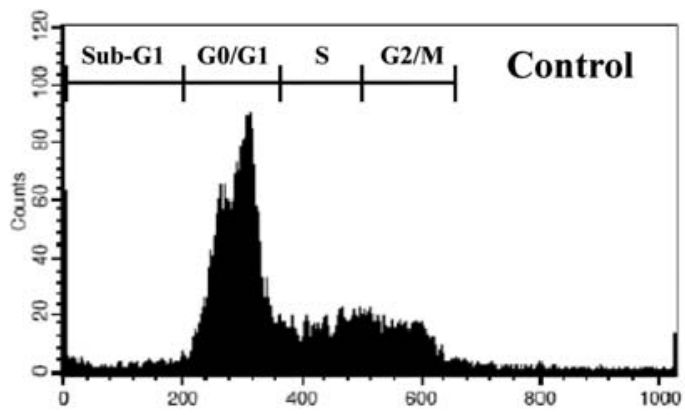

Sub-G1: $\quad 2.25 \%$

G0/G1: $55.21 \%$

S: $15.32 \%$

G2/M: $29.47 \%$

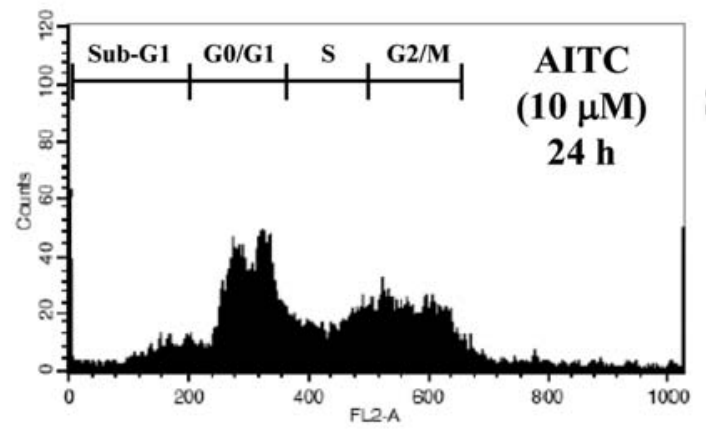

Sub-G1: $26.36 \%$

G0/G1: $34.58 \%$

S: $23.26 \%$

G2/M: $42.16 \%$

B
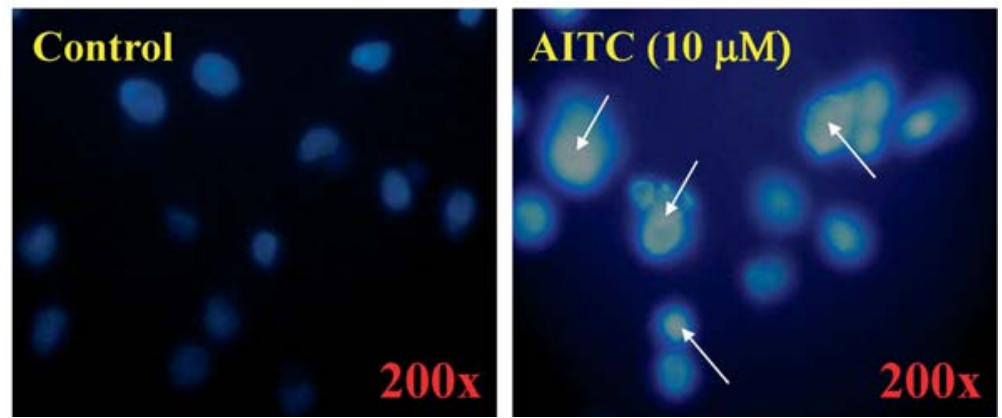

Figure 2. Effects of AITC on cell cycle distribution (A) and chromatin condensation (B) in GBM 8401 cells. Cells were treated with $10 \mu \mathrm{M}$ of AITC for $24 \mathrm{~h}$ and then were analyzed and determined for cell cycle distribution by PI staining and flow cytometric analysis. AITC induced chromatin condensation (an apoptotic characteristic) in GBM 8401 cells. Cells were incubated with $10 \mu \mathrm{M}$ of AITC for $24 \mathrm{~h}$ and apoptotic cells were determined by DAPI staining and were photographed by fluorescence microscopy (x200) as described in Materials and methods.

showed that a significant decrease of CDK1 activity (Fig. 3A) and down-regulated the protein levels, including CDK1, cyclin $\mathrm{B}$ and cyclin A as shown in Fig. 3B.

AITC enhances caspase-3 and -9 activities and stimulates the associated mitochondrial apoptotic signaling proteins. To further confirm that AITC-induced apoptotic cell death, the results of Western blot analysis from $10 \mu \mathrm{M}$ of AITC coincubation with GBM 8401 cells for $0,6,12,24$ and $48 \mathrm{~h}$ are shown in Fig. 4A. The increasing protein levels of cytochrome $c$, Apaf-1, pro-caspase-9, AIF, and Endo G in cytosolic fractions may contribute to the occurrence of AITC-triggered mitochondrial apoptosis and this signaling was timedependent. The results are shown in Fig. 4B, indicating that AITC induced a significant rise in caspase- 3 and -9 activities rather than influence of caspase- 8 response. This stimulation of activity of the caspase cascade in GBM 8401 cells was reduced after pre-incubation with specific inhibitors of caspase- 3 and -9 , respectively. Based on these results, AITCinduced cell death was correlated with caspase-dependent and -independent mitochondrial apoptotic pathways.

\section{Discussion}

Isothiocyanates (ITCs) have been reported to have anticancer effects in both in vitro and in vivo experimental models (31-33). AITC, also known as mustard oil and existing in dietary cruciferous vegetables, is one of the common naturally occurring isothiocyanates (ITCs) $(34,35)$. It is demonstrated that AITC promoted cell cycle arrest $(36,37)$ and induced apoptosis $(34,38)$ in many types of cancer cells. Therefore, AITC may have potential as dietary chemoprevention/treatment agent (34). However, there is no information on AITC in having anti-cancer activity of human brain malignant glioma cell line and the in vitro study of brain cancer GBM 8401 cells is lacking. In this study, we investigated AITC triggered G2/M phase arrest and apoptosis in GBM 8401 cells. We showed that AITC: 1) induced morphological changes; 2) decreased the percentage of viable cells; 3 ) increased G2/M phase arrest; 4) stimulated the levels of caspase-9, -3, AIF and Endo G through a mitochondriadependent apoptotic pathway. We examined the effects of AITC on the survival of GBM 8401 cells and our results 
A

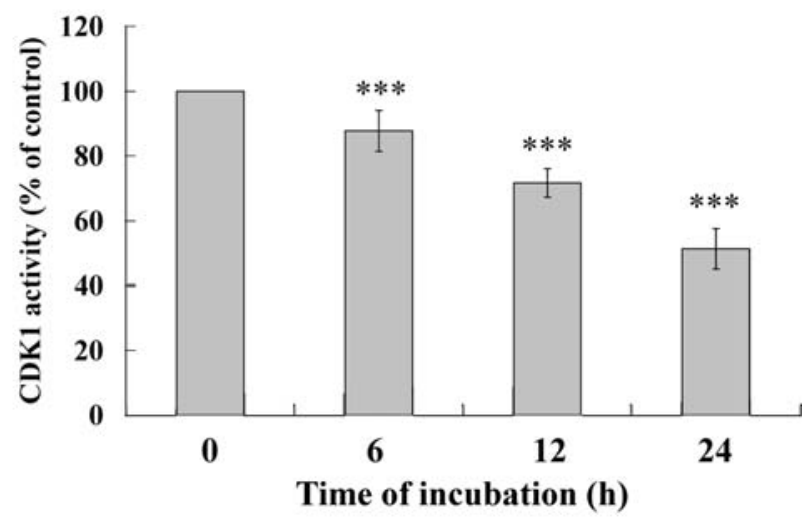

B

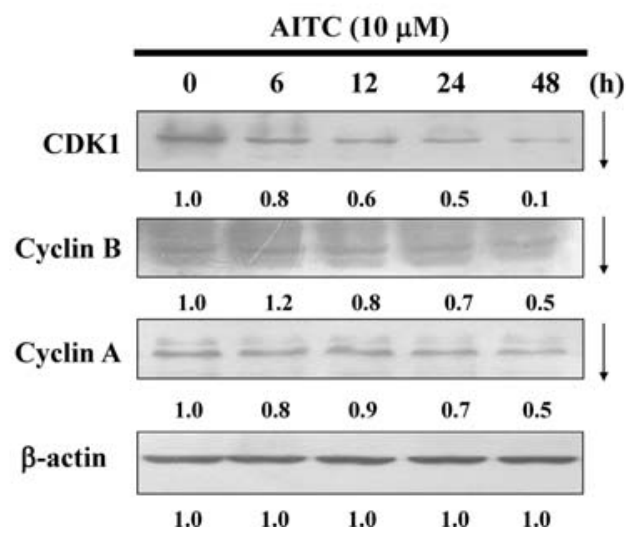

Figure 3. AITC alters the levels of CDK1 activity (A), and the CDK1, cyclin A and cyclin B proteins of G2/M phase arrest in GBM 8401 cells. Cells were incubated with $10 \mu \mathrm{M}$ AITC for $0,6,12$, and $24 \mathrm{~h}$ for CDK1 activity. GBM 8401 cells were incubated with $10 \mu$ M AITC for $0,6,12,24$ and $48 \mathrm{~h}$, harvested from each sample and then relative protein levels were determined by Western blot analysis. The levels of CDK1, cyclin B and cyclin A were examined, and $B$-actin as an internal control using SDS-PAGE and Western blotting as described in Materials and methods. ${ }^{* * *} \mathrm{P}<0.001$, significantly different compared to the control group.

showed that AITC induced cytotoxic responses in a dosedependent manner. Also, AITC stimulated morphological changes such as rounding and shrinkage in GBM 8401 cells after 24 and 48 h-treatment.

Cell growth and proliferation of mammalian and tumor cells occur through cell cycle progression. The inhibition of cell cycle distribution has been recognized as a target for anticancer agents $(39,40)$. The results in the present study show that GBM 8401 cells were treated with $10 \mu \mathrm{M}$ of AITC for up to $24 \mathrm{~h}$ predominantly accumulated in the $\mathrm{G} 2 / \mathrm{M}$ phase by flow cytometric analysis, suggesting the sequential events of cell cycle arrest followed by apoptosis. This finding agrees with another study on causing G2/M phase arrest in human prostate cancer cells (36). Furthermore, it is reported that the CDK1/Cyclin B complex is one of the major regulators leading the $\mathrm{G} 2$ to $\mathrm{M}$ progression or apoptosis (24). We investigated the GBM 8401 cells after AITC treatment determining the $\mathrm{G} 2 / \mathrm{M}$ phase regulated protein levels and the data showed that a decrease in the protein levels of CDK1, cyclin B and cyclin A by Western blot analysis, and CDK1 kinase assays revealed reduction of CDK1 activity at 6,12 and $24 \mathrm{~h}$ after $10 \mu \mathrm{M}$ of AITC treatment.
A

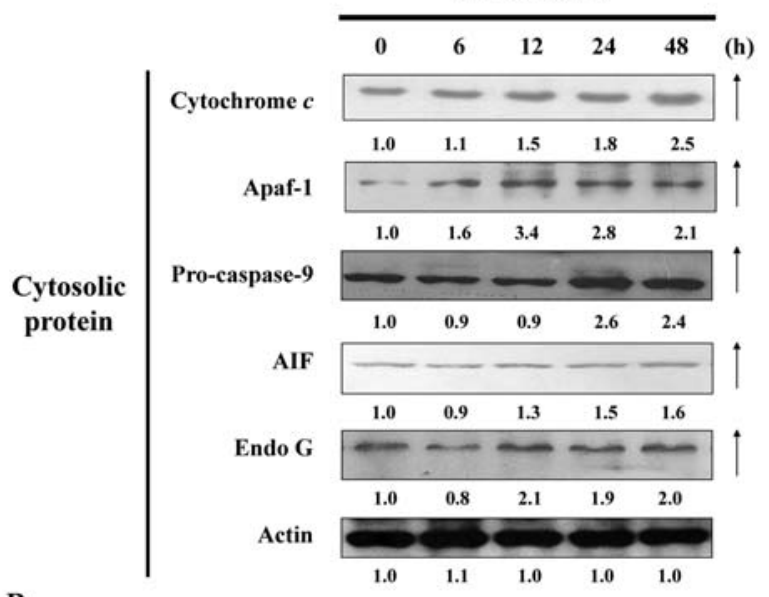

B

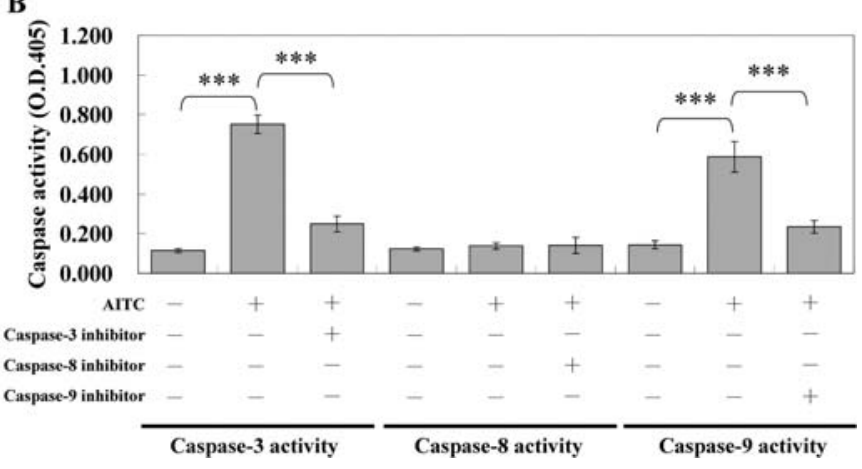

Figure 4. AITC affects the relative protein levels of apoptosis (A) and caspase- $3,-8$ and -9 activities (B) in GBM 8401 cells. Cells were incubated with $10 \mu \mathrm{M}$ AITC for $0,6,12$, and $24 \mathrm{~h}$ then harvested from each sample, and the cytosolic proteins were prepared then detected by Western blotting. The level expressions of cytochrome $c$, Apaf-1, pro-caspase-9, AIF and Endo G were examined using SDS-PAGE and Western blotting. Cells were preincubated with or without inhibitors of caspase-3 (Z-DEVE-FMK), caspase-8 (Z-IETD-FMK) and caspase-9 (Z-LEHD-FMK), respectively for $3 \mathrm{~h}$ and then treated with $10 \mu \mathrm{M}$ AITC for $24 \mathrm{~h}$. AITC stimulated the activities of caspase-3 and -9 of GBM 8401 cells and it was determined as described in Materials and methods. ${ }^{* * *} \mathrm{P}<0.001$, significant difference.

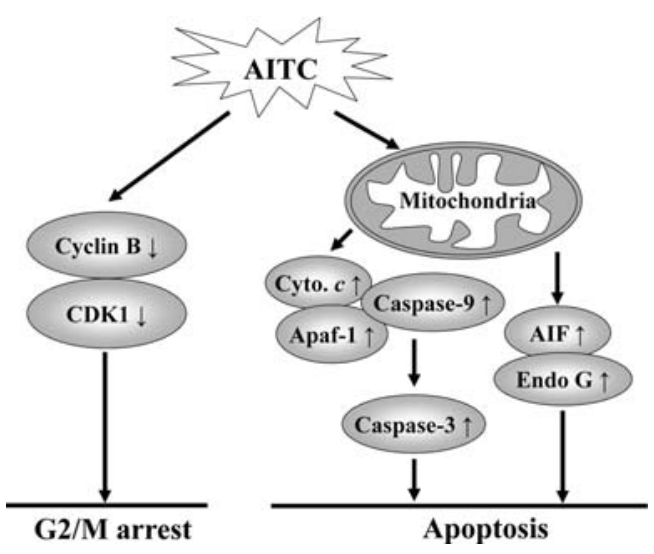

Figure 5. The proposed model of AITC-mediated G2/M phase arrest and apoptosis in human brain malignant glioma GBM 8401 cells.

Induction of apoptotic cell death is one of the best strategies for cancer treatment $(10,41)$. Our results indicated that AITC induced apoptosis in GBM 8401 cells as demonstrated by 
flow cytometric analysis and DAPI staining was applied to confirm cell apoptosis in examined GBM 8401 cells. These results corroborate findings of other studies on several different cancer cell lines $(34,36-38,42)$. Furthermore, apoptotic cell death is a genetically regulated biological process and it can be divided into extrinsic and intrinsic signaling major pathways $(43,44)$. The members of Bcl-2 family act as repressors of apoptosis and mitochondrial dysfunction by releasing of apoptotic factors such as cytochrome $c$, apoptosis-inducing factor (AIF), and endonuclease G (Endo G), cytochrome $c$, once released into the cytosol, interacts with Apaf-1, leading to the activation of caspase- 9 pro-enzymes. Active caspase- 9 activates caspase-3, which subsequently activates the rest of the caspase cascade and leads to cell apoptosis through mitochondria-dependent pathway (45). The AIF and Endo G also triggered apoptosis through a caspase-independent pathway (46). The results from the Western blot analysis showed that AITC increased protein levels of cytochrome $c$, Apaf-1, pro-caspase-9, AIF, and Endo G, suggesting that analyses of protein abundance indicated that AITC induced apoptosis through a mitochondria-dependent pathway. Also, AITC stimulates the loss of mitochondrial membrane potential $\left(\Delta \Psi_{m}\right)$ resulting from the mitochondria dysfunction (data not shown). The activation of the caspase cascade is the major mechanism that promotes apoptosis in response to death-inducing signals from mitochondria stress $(43,47)$. In this study, we observed the AITC induced caspase- 9 and -3 activities in GBM 8401 and the specific inhibitors (Z-DEVEFMK for caspase-3 and Z-LEHD-FMK for caspase-9) individually prevented AITC-induced caspase-3 and -9 activities, respectively in GBM 8401 cells.

The schematic proposed model of AITC-mediated G2/M phase arrest and apoptosis in human brain malignant glioma GBM 8401 cells is shown in Fig. 5. In conclusion, AITC mediated G2/M phase arrest and induced apoptosis in human brain malignant glioma GBM 8401 cells. AITC decreased the regulated protein levels of cyclin $\mathrm{B}$ and $\mathrm{CDK} 1$ and then led to $\mathrm{G} 2 / \mathrm{M}$ phase arrest. AITC-stimulated apoptotic cell death resulted in the alteration of a series of mitochondrial dysfunction and apoptotic signaling. AITC increased the activity of caspase-9, and -3 , and the release of mitochondrial cytochrome $c$, AIF and Endo G leading to cell apoptosis.

\section{Acknowledgements}

The investigation was supported by a research grant from the National Science Council of the Republic of China (NSC 962321-B-039-007) and grants from China Medical University, Taichung, Taiwan (CMU96-114).

\section{References}

1. Wen PY and Kesari S: Malignant gliomas in adults. N Engl J Med 359: 492-507, 2008.

2. Buckner JC: Factors influencing survival in high-grade gliomas. Semin Oncol 30: 10-14, 2003.

3. Deorah S, Lynch CF, Sibenaller ZA and Ryken TC: Trends in brain cancer incidence and survival in the United States: Surveillance, Epidemiology, and End Results Program, 1973 to 2001. Neurosurg Focus 20: E1, 2006.

4. Kanu OO, Hughes B, Di C, et al: Glioblastoma multiforme oncogenomics and signaling pathways. Clin Med Oncol 3: 39-52, 2009 .
5. Rimando AM and Suh N: Natural products and dietary prevention of cancer. Mol Nutr Food Res 52 (Suppl 1): S5, 2008.

6. Vazquez A, Bond EE, Levine AJ and Bond GL: The genetics of the p53 pathway, apoptosis and cancer therapy. Nat Rev Drug Discov 7: 979-987, 2008.

7. Hayes JD, Kelleher MO and Eggleston IM: The cancer chemopreventive actions of phytochemicals derived from glucosinolates. Eur J Nutr 47 (Suppl 2): 73-88, 2008.

8. Malumbres M and Barbacid M: Cell cycle, CDKs and cancer: a changing paradigm. Nat Rev Cancer 9: 153-166, 2009.

9. Krempler A, Deckbar D, Jeggo PA and Lobrich M: An imperfect G2M checkpoint contributes to chromosome instability following irradiation of S and G2 phase cells. Cell Cycle 6: 1682-1686, 2007.

10. Batista LF, Kaina B, Meneghini R and Menck CF: How DNA lesions are turned into powerful killing structures: insights from UV-induced apoptosis. Mutat Res 681: 197-208, 2009.

11. Clark GB, Thompson G Jr and Roux SJ: Signal transduction mechanisms in plants: an overview. Curr Sci 80: 170-177, 2001.

12. Lin HL, Yang JS, Yang JH, et al: The role of $\mathrm{Ca}^{+}$on the DADSinduced apoptosis in mouse-rat hybrid retina ganglion cells (N18). Neurochem Res 31: 383-393, 2006.

13. Debatin KM and Krammer PH: Death receptors in chemotherapy and cancer. Oncogene 23: 2950-2966, 2004.

14. Fulda S and Debatin KM: Extrinsic versus intrinsic apoptosis pathways in anticancer chemotherapy. Oncogene 25: 4798-4811, 2006.

15. Thornberry NA and Lazebnik Y: Caspases: enemies within. Science 281: 1312-1316, 1998.

16. Saelens X, Festjens N, Vande Walle L, van Gurp M, van Loo G and Vandenabeele P: Toxic proteins released from mitochondria in cell death. Oncogene 23: 2861-2874, 2004.

17. Wajant H: The Fas signaling pathway: more than a paradigm. Science 296: 1635-1636, 2002.

18. Fahey JW, Zalcmann AT and Talalay P: The chemical diversity and distribution of glucosinolates and isothiocyanates among plants. Phytochemistry 56: 5-51, 2001.

19. Zhang Y, Tang L and Gonzalez V: Selected isothiocyanates rapidly induce growth inhibition of cancer cells. Mol Cancer Ther 2: 1045-1052, 2003.

20. Tang L and Zhang Y: Dietary isothiocyanates inhibit the growth of human bladder carcinoma cells. J Nutr 134: 2004-2010, 2004.

21. Hasegawa T, Nishino $H$ and Iwashima A: Isothiocyanates inhibit cell cycle progression of HeLa cells at G2/M phase. Anticancer Drugs 4: 273-279, 1993.

22. Smith TK, Lund EK, Parker ML, Clarke RG and Johnson IT: Allyl-isothiocyanate causes mitotic block, loss of cell adhesion and disrupted cytoskeletal structure in HT29 cells. Carcinogenesis 25: 1409-1415, 2004

23. Wang DY, Yeh CC, Lee JH, Hung CF and Chung JG: Berberine inhibited arylamine $\mathrm{N}$-acetyltransferase activity and gene expression and DNA adduct formation in human malignant astrocytoma (G9T/VGH) and brain glioblastoma multiforms (GBM 8401) cells. Neurochem Res 27: 883-889, 2002.

24. Yang JS, Chen GW, Hsia TC, et al: Diallyl disulfide induces apoptosis in human colon cancer cell line (COLO 205) through the induction of reactive oxygen species, endoplasmic reticulum stress, caspases casade and mitochondrial-dependent pathways. Food Chem Toxicol 47: 171-179, 2009.

25. Zhao D, Gong T, Fu Y, et al: Lyophilized Cheliensisin A submicron emulsion for intravenous injection: characterization, in vitro and in vivo antitumor effect. Int J Pharm 357: 139-147, 2008.

26. Huang AC, Lin TP, Weng YS, et al: Ethyl 2-[N-m-chlorobenzyl(2'-methyl)] anilino-4-oxo-4,5-dihydrofuran-3-carboxylate (JOT01006) induces apoptosis in human cervical cancer HeLa cells. Anticancer Res 27: 2505-2514, 2007.

27. Yang JS, Hour MJ, Kuo SC, Huang LJ and Lee MR: Selective induction of G2/M arrest and apoptosis in HL-60 by a potent anticancer agent, HMJ-38. Anticancer Res 24: 1769-1778, 2004.

28. Kuo HM, Tsai HC, Lin YL, et al: Mitochondrial-dependent caspase activation pathway is involved in baicalein-induced apoptosis in human hepatoma J5 cells. Int J Oncol 35: 717-724, 2009.

29. Chung JG, Yang JS, Huang LJ, et al: Proteomic approach to studying the cytotoxicity of YC-1 on U937 leukemia cells and antileukemia activity in orthotopic model of leukemia mice. Proteomics 7: 3305-3317, 2007. 
30. Packard BZ, Toptygin DD, Komoriya A and Brand L: Profluorescent protease substrates: intramolecular dimers described by the exciton model. Proc Natl Acad Sci USA 93: 11640-11645, 1996.

31. Hwang ES and Lee HJ: Benzyl isothiocyanate inhibits metalloproteinase-2/-9 expression by suppressing the mitogenactivated protein kinase in SK-Hep1 human hepatoma cells. Food Chem Toxicol 46: 2358-2364, 2008.

32. Kumar A, D'Souza SS, Tickoo S, Salimath BP and Singh HB: Antiangiogenic and proapoptotic activities of allyl isothiocyanate inhibit ascites tumor growth in vivo. Integr Cancer Ther 8: 75-87, 2009.

33. Nakamura Y: Chemoprevention by isothiocyanates: molecular basis of apoptosis induction. Forum Nutr 61: 170-181, 2009

34. Zhang Y: Allyl isothiocyanate as a cancer chemopreventive phytochemical. Mol Nutr Food Res 54: 127-135, 2010.

35. Kushad MM, Brown AF, Kurilich AC, et al: Variation of glucosinolates in vegetable crops of Brassica oleracea. J Agric Food Chem 47: 1541-1548, 1999.

36. Xiao D, Srivastava SK, Lew KL, et al: Allyl isothiocyanate, a constituent of cruciferous vegetables, inhibits proliferation of human prostate cancer cells by causing $\mathrm{G} 2 / \mathrm{M}$ arrest and inducing apoptosis. Carcinogenesis 24: 891-897, 2003.

37. Smith T, Musk SR and Johnson IT: Allyl isothiocyanate selectively kills undifferentiated HT29 cells in vitro and suppresses aberrant crypt foci in the colonic mucosa of rats. Biochem Soc Trans 24: S381, 1996.

38. Srivastava SK, Xiao D, Lew KL, et al: Allyl isothiocyanate, constituent of cruciferous vegetables, inhibits growth of PC-3 human prostate cancer xenografts in vivo. Carcinogenesis 24 : $1665-1670,2003$.
39. Schwartz GK and Shah MA: Targeting the cell cycle: a new approach to cancer therapy. J Clin Oncol 23: 9408-9421, 2005.

40. Kim SJ, Min HY, Chung HJ, et al: Inhibition of cell proliferation through cell cycle arrest and apoptosis by thio-Cl-IB-MECA, a novel A3 adenosine receptor agonist, in human lung cancer cells. Cancer Lett 264: 309-315, 2008.

41. Sanchez-Munoz A, Perez-Ruiz E, Mendiola Fernandez C, Alba Conejo E and Gonzalez-Martin A: Current status of antiangiogenic agents in the treatment of ovarian carcinoma. Clin Transl Oncol 11: 589-595, 2009.

42. Bhattacharya A, Tang L, Li Y, et al: Inhibition of bladder cancer development by allyl isothiocyanate. Carcinogenesis 31 : 281-286, 2010.

43. Petit E, Oliver L and Vallette FM: The mitochondrial outer membrane protein import machinery: a new player in apoptosis? Front Biosci 14: 3563-3570, 2009.

44. Murgia M, Giorgi C, Pinton P and Rizzuto R: Controlling metabolism and cell death: at the heart of mitochondrial calcium signalling. J Mol Cell Cardiol 46: 781-788, 2009.

45. Kagan VE, Bayir HA, Belikova NA, et al: Cytochrome c/ cardiolipin relations in mitochondria: a kiss of death. Free Radic Biol Med 46: 1439-1453, 2009.

46. Cai J, Wang M, Li B, Wang C, Chen Y and Zuo Z: Apoptotic and necrotic action mechanisms of trimethyltin in human hepatoma G2 (HepG2) cells. Chem Res Toxicol 22: 1582-1587, 2009.

47. Ziegler DS and Kung AL: Therapeutic targeting of apoptosis pathways in cancer. Curr Opin Oncol 20: 97-103, 2008. 